\title{
Listening for a needle in a haystack: passive acoustic detection of dolphins at very low densities
}

\author{
William Rayment ${ }^{1, *}$, Steve Dawson ${ }^{1}$, Silvia Scali ${ }^{1}$, Liz Slooten $^{2}$ \\ ${ }^{1}$ Department of Marine Science and ${ }^{2}$ Department of Zoology, University of Otago, PO Box 56, Dunedin, New Zealand
}

\begin{abstract}
Passive acoustic surveys have potential for detecting trends in abundance and habitat use by rare cetaceans. We deployed commercially available acoustic data loggers (T-PODs) in 4 harbours on the west coast of New Zealand's North Island between 2005 and 2008 to investigate the distribution of Maui's dolphin Cephalorhynchus hectori maui and assess whether current protection measures are sufficient. A set of decision rules was developed to minimise the potential for false positive detections. Over 3211 'T-POD days' of acoustic monitoring, 39 click trains which satisfied all of our decision rules were detected, indicating the presence of Maui's dolphins in Manukau and Kaipara Harbours. Data from the site with the most detections were fitted to 3 models, showing that the number of detections varied temporally $(p<0.001)$. The models were also used to show to what degree dolphins could have been present at monitored locations yet remain undetected. The study highlighted the challenges of passive acoustic monitoring of rare species, particularly of small delphinids in an environment which is both physically and acoustically challenging. Nonetheless, we demonstrated that T-PODs are effective in studies of Maui's dolphin distribution, that Maui's dolphins are found in North Island harbours and remain at risk from gillnet bycatch. We make a number of recommendations concerning acoustic monitoring studies of rare cetaceans, principally that a thorough understanding of the target signals and the acoustic environment being monitored is essential for maximising acoustic detection rates.
\end{abstract}

KEY WORDS: Maui's dolphin · Cephalorhynchus hectori maui · T-POD · Passive acoustic monitoring · Bycatch Resale or republication not permitted without written consent of the publisher

\section{INTRODUCTION}

Passive acoustics are increasingly used for detecting cetaceans, complementing visual survey methods. They can be operated continuously and autonomously for long periods of time and are less reliant on good weather conditions (Mellinger et al. 2007). Acoustic methods often have higher detection rates than visual surveys, particularly when the target species is cryptic (e.g. finless porpoise Neophocaena phocaenaoides, Akamatsu et al. 2008) or occurs at low densities (e.g. northern right whale Eubalaena glacialis, Clark et al. 2010). Furthermore, in areas of very low density, visual surveys are likely to have very high variance, resulting in low power to detect population trends or effects of impacts (Taylor \& Gerrodette 1993, Carstensen et al. 2006). For these reasons, researchers working with the Critically Endan- gered vaquita Phocoena sinus (Rojas-Bracho et al. 2008) are using passive acoustic methods to monitor the effectiveness of the species' recovery plan (Rojas-Bracho et al. 2010).

With a range restricted to the west coast of New Zealand's North Island, and with a population estimate of 111 individuals $(\mathrm{CV}=44 \%)$, the Critically Endangered Maui's dolphin Cephalorhynchus hectori maui (Reeves et al. 2008) is one of the rarest marine mammals in the world (Slooten et al. 2006). Current abundance is estimated to be about $7 \%$ of that in 1970, principally due to bycatch in gillnet fisheries (Slooten 2007 , Slooten \& Dawson 2010). Although most frequently sighted on the open coast, Maui's dolphins have been seen in at least 3 North Island harbours (Kaipara, Manukau and Raglan, Slooten et al. 2005; Fig. 1). Quantifying their use of this habitat is critical for con- 


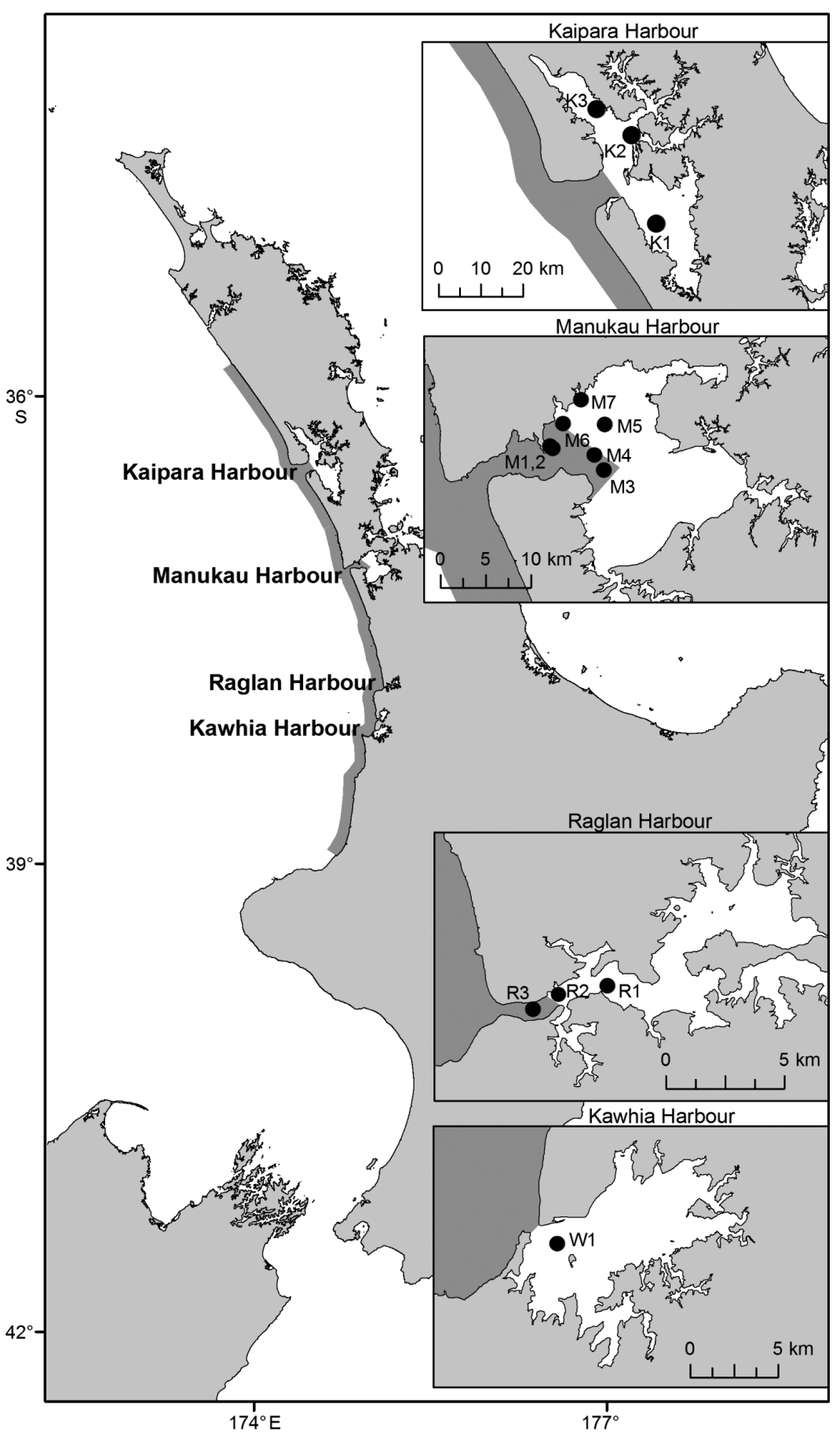

Fig. 1. Locations of the 4 North Island (New Zealand) harbours included in the passive acoustic monitoring study. Insets show locations of acoustic data logger (T-POD) deployments. The area shaded dark grey depicts the protected area where gillnetting is now prohibited

servation reasons because despite a gillnet ban up to 7 nautical miles from the coast, gillnetting is still permitted inside these harbours (Ministry of Fisheries 2008; Fig. 1). Low densities mean that the level of effort required to detect Maui's dolphins by visual surveys of the harbours is not feasible. We therefore chose acoustic methods for this study.

The T-POD (Chelonia) is a commercially available acoustic data logger, which has been employed extensively in studies of habitat use by small cetaceans (e.g. Carstensen et al. 2006, Verfuß et al. 2007, Bailey et al. 2010). It has already been shown that T-PODs work well with Hector's dolphins Cephalorhynchus hectori hectori. They have been used to monitor temporal and spatial variation in habitat use (Rayment et al. 2009a), although the detection range (effective detection radius $=198 \mathrm{~m}$, maximum detection range $=431 \mathrm{~m}$ ) results in relatively limited spatial coverage (Rayment et al. 2009b). The echolocation signals of Maui's dolphins and Hector's dolphins are very similar (S. Dawson unpubl. data), as are the echolocation signals of the different species in the genus Cephalorhynchus (Morisaka et al. 2011). Hence, T-PODs were an obvious choice for acoustic monitoring. We deployed TPODs in 4 North Island harbours, focussing on 4 questions: (1) Were harbours part of the normal habitat of Maui's dolphins, as suggested by opportunistic visual sightings? (2) Did Maui's dolphins range beyond the areas currently protected? (3) Was the number of detections at each site similar across the $3 \mathrm{yr}$ of the study? (4) What could be concluded about habitat use from a lack of detections?

\section{MATERIALS AND METHODS}

T-POD deployments. T-PODs were deployed at 7 locations in Manukau Harbour, 3 in Kaipara Harbour, 3 in Raglan Harbour and 1 location in Kawhia Harbour (Fig. 1). In total, 110 successful deployments between October 2005 and August 2008 resulted in 3211 'T-POD days' of acoustic monitoring. The majority of effort was in Manukau Harbour (Table 1, Fig. 2), where the highest number of Maui's dolphin sightings have been reported (Slooten et al. 2005). Effort was partitioned into austral summer (October to March) and austral winter (April to September) as there is evidence of seasonal differences in distribution for other Hector's dolphin populations (Dawson \& Slooten 1988, 
Table 1. Monitoring effort (in number of deployment days) and numbers of 'Cet All' click train detections in the 4 North Island harbours. Detections satisfying Decision Rules 1 to 5 (see Table 2) were deemed to have originated from Maui's dolphins, while additional detections satisfying Rules 1 to 4 were deemed to be of cetacean origin but not from Maui's dolphins

\begin{tabular}{|lcccc|}
\hline Harbour & $\begin{array}{c}\text { Effort } \\
\text { (d) }\end{array}$ & $\begin{array}{c}\text { No. of } \\
\text { 'Cet All' } \\
\text { detections }\end{array}$ & $\begin{array}{c}\text { No. of Maui's } \\
\text { dolphin } \\
\text { detections }\end{array}$ & $\begin{array}{c}\text { No. of non- } \\
\text { Maui's cetacean } \\
\text { detections }\end{array}$ \\
\hline Kaipara & 632 & 108 & 1 & 14 \\
Kawhia & 186 & 3 & 0 & 0 \\
Manukau & 1883 & 300 & 38 & 3 \\
Raglan & 510 & 100 & 0 & 0 \\
\hline
\end{tabular}

Rayment et al. 2010). In total, 23 T-PODs were used during the course of the study; 4 version 3, 6 version 4 and 13 version 5 T-PODs. Data were processed with TPOD.exe v8.24. Seven T-PODs were lost during the course of the study.

Other cetacean species known to use the habitat are bottlenose dolphins Tursiops spp., common dolphins Delphinus delphis and orca Orcinus orca. These species use echolocation signals which are broadband, with a variable, and typically lower, peak frequency than those of Cephalorhynchus dolphins (Au 1993, Au et al. 2004, Morisaka et al. 2011). In all T-POD deploy- ments, 5 scans were optimised for the detection of Maui's dolphins (target filter frequency $=130 \mathrm{kHz}$; reference frequency $=92 \mathrm{kHz}$; bandwidth $=5$; noise adaptation $=++$; sensitivity $=10$; scan limit $=240$ ), and 1 scan was set at a lower frequency to discriminate between Maui's dolphins and other delphinids (target filter frequency $=50 \mathrm{kHz}$; reference frequency $=$ $70 \mathrm{kHz}$; sensitivity $=6$ ). A similar strategy has been employed to discriminate between detections of harbour porpoises and bottlenose dolphins in other studies using T-PODs (e.g. Philpott et al. 2007, Bailey et al. 2010).

The T-POD software classifies detections of click trains according to how likely they are to be of cetacean origin. The classification algorithm is not documented and therefore the process is not transparent. Using theodolite observations of Hector's dolphins in the vicinity of a moored T-POD, Rayment et al. (2009b) found that all 'Cet All' detections (includes the 2 categories deemed to be most likely of cetacean origin) were highly likely to be from Hector's dolphins (none were made when dolphins were not present in the bay) and that the majority of 'Doubtful' detections were also from Hector's dolphins. However, in the present study, close examination of T-POD records revealed that many detections classified as 'Cet All' were likely to have been noise of non-cetacean origin. We therefore developed a set of decision rules (Table 2), based on

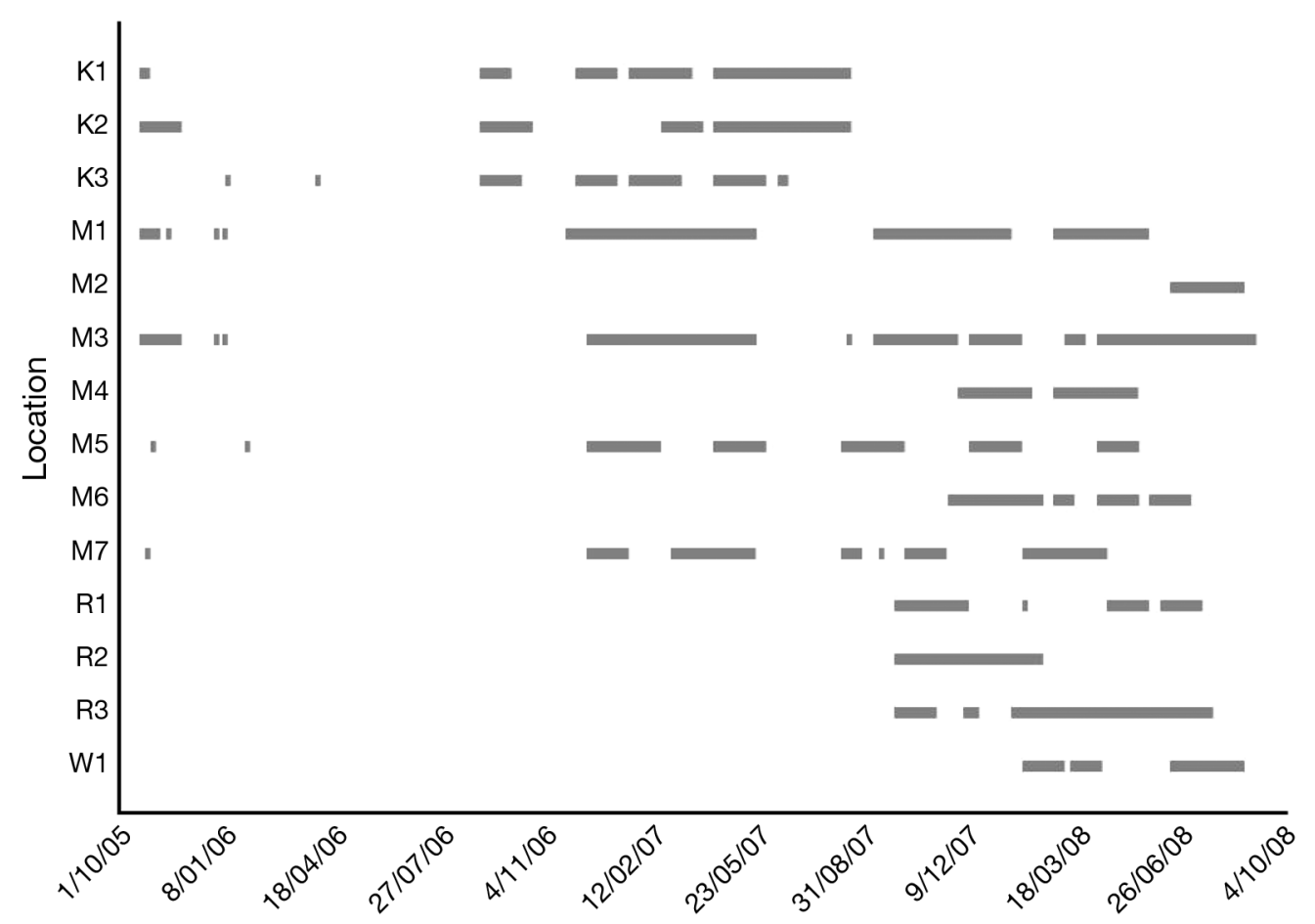

Fig. 2. Temporal distribution of T-POD deployments at the 14 North Island harbour locations. Dates are dd/mm/yy and locations are coded as in Fig. 1 
T-POD detections with concurrent visual sightings of Hector's dolphins (Rayment et al. 2009b). All click trains classified as 'Cet All' detections were viewed graphically in the T-POD software and their train details exported. A click train was only accepted as a Maui's dolphin detection if it was categorised by TPOD.exe as 'Cet All' and satisfied all of our decision rules. Additionally, we checked if any click trains apparently arising from boat sonar were detected within $10 \mathrm{~min}$ of each 'Cet All' detection. If so, click trains with slow pulse repetition frequencies (PRFs; $<20$ clicks s $^{-1}$ ) and long click durations (>200 $\mu$ s) were treated with additional caution. The characteristics (number of clicks per train, mean PRF and mean click duration) of click trains accepted as originating from Maui's dolphins were compared with those rejected using Mann-Whitney U-tests.

Data analysis. Despite the high level of acoustic monitoring effort, detections which satisfied our decision rules were made at only 2 locations during 3 T-POD deployments. With so few detections, it was difficult to make detailed spatial and temporal comparisons. We therefore modelled the distribution of detections at Cornwallis Point (M1 in Fig. 1) in summer 2005/6, the only location and time period with sufficient detections, in order to make inferences about the lack of detections in the subsequent seasons. During the 2005/6 summer, there were 37 detections of Maui's dolphins from 5 separate days during $38 \mathrm{~d}$ of acoustic monitoring. The data were sparse and highly overdispersed $\left(\right.$ mean $\pm \mathrm{SD}=0.97 \pm 3.24$ detections $\mathrm{d}^{-1}$ ), so it was not clear which was the most appropriate model to fit. We therefore trialled 3 different models and compared the results:

(1) A binomial model with presence (1) or absence (0) of acoustic detections scored on each monitoring day.

(2) A 0-inflated binomial model (Hall 2000), with presence or absence of detections scored for (a) each monitoring day and (b) $1 \mathrm{~h}$ duration sub-units $(\mathrm{n}=24)$ within each day.
(3) A negative binomial model (Ludwig \& Reynolds 1988) with monitoring day as the sampling unit.

Using the parameters of these distributions, the probability of obtaining the observed number of acoustic detections of Maui's dolphins could be calculated for all deployments of T-PODs at Cornwallis Point. This essentially tests the hypothesis that the level of detections at Cornwallis Point was equal across all seasons.

Our last question was what level of use of the harbours by Maui's dolphins could go undetected by the acoustic monitoring effort we employed? To address this, we calculated the probability of observing 0 acoustic detections in $153 \mathrm{~d}$ (our longest T-POD deployment) for distributions with a varying number of days on which dolphins were theoretically detected. The critical level of use was defined as the maximum number of days dolphins could theoretically have been present, which resulted in a probability of observing 0 detections greater than or equal to the critical alpha level (0.05). The critical level of use was calculated for the 3 distributions trialled: binomial, 0-inflated binomial and negative binomial.

Finally, we calculated the proportion of Manukau Harbour available to Maui's dolphins which was effectively monitored by the T-PODs. The area deeper than the $2 \mathrm{~m}$ isobath on a digitised nautical chart (NZ 4314) was measured using the software Image J. The area monitored was estimated using the effective detection radius for T-PODs with Hector's dolphins (198 m; Rayment et al. 2009b) and the number of monitoring locations.

\section{RESULTS}

Over the 3211 T-POD days of acoustic monitoring in the 4 harbours, 511 click trains classified as 'Cet All' were detected by the T-PODs (Table 1). Of these, only 39 trains satisfied all of our decision rules and were

Table 2. Decision rules employed in determining whether 'Cet All' detections should be classified as Maui's dolphins Cephalorhynchus hectori maui. PRF: pulse repetition frequency
Rule
Justification
(1) $\geq 8$ clicks in train
(2) Mean click duration $<300 \mu \mathrm{s}$
(3) Smooth trend in PRFs, but PRFs not constant
(4) No accompanying noise around focal click train (by viewing all clicks in TPOD.exe)
(5) No trains on Scan 6 detected within 10 min of focal train
Longer trains less likely to arise by chance $(97.3 \%$ of 714 'Cet All' trains in Rayment et al. 2009b had $\geq 8$ clicks)
Long clicks likely to be of non-cetacean origin (all 714 'Cet All' trains in Rayment et al. 2009b had mean click duration <300 $\mu \mathrm{s}$ )
PRFs in click trains from cetaceans can change rapidly but have a smooth trend. Trains with very constant PRFs likely to arise from boat sonar TPOD.exe can occasionally select a plausible click train from random noise
Trains likely to be of cetacean origin but not Maui's dolphin 
deemed to have originated from Maui's dolphins. The detections of Maui's dolphins came from Cornwallis Point (M1; Fig. 1) in Manukau Harbour in November 2005 (37 detections on 5 different days, 4 of which were consecutive) and November 2007 (1 detection), and K1 in Kaipara Harbour (Fig. 1) in December 2006 (1 detection). The detections from Manukau Harbour were inside the area where gillnetting is now prohibited, while the detection from Kaipara Harbour was outside the protected area (Fig. 1). No 'Cet All' detections which satisfied all of our decision rules were made in either Kawhia or Raglan Harbours. A further 17 trains satisfied all of the decision rules except Rule 5 (see Table 2), and were classified as being of cetacean origin, but not from Maui's dolphins (Table 1). Therefore, the majority of 'Cet All' trains (90\%) were rejected as cetacean click trains for one or more reasons. The most common reason for rejection was the presence of accompanying noise around the focal click train $(67 \%)$, followed by PRFs not changing smoothly $(48 \%)$, too few clicks $(24 \%)$ and excessively long click durations $(1 \%)$. All of the tested characteristics of the click trains accepted as originating from Maui's dolphins were significantly different from those rejected (number of clicks per train, $W=11450, \mathrm{p}=0.03$; mean PRF, $W=5192.5, \mathrm{p}=2.70 \times$ $10^{-6}$; mean click duration, $W=14341.5, \mathrm{p}=7.95 \times 10^{-8}$ ).

Three models (binomial, 0-inflated binomial and negative binomial) were fitted to the detection data from Cornwallis Point in Manukau Harbour during summer 2005/06. These distributions were used to estimate the probability of obtaining the observed number of acoustic detections at Cornwallis Point in the subsequent seasons. The probabilities from all 3 distributions were remarkably similar and all were $<0.001$ (Table 3). The hypothesis that the level of detections at Cornwallis Point was equal across all seasons was therefore rejected.

The 3 models were also used to calculate the probability of 0 acoustic detections given a varying level of use of the harbours. For all 3 distributions, the maximum level of use resulting in a probability of no detections in $153 \mathrm{~d}$ being $\geq 0.05$ was $2 \mathrm{~d}$.

Table 3. Monitoring effort (in number of deployment days), number of Maui's dolphin detections and probabilities of obtaining the observed number of Maui's dolphin detections at Cornwallis Point (M1 in Fig. 1) using 3 model scenarios, assuming the distribution of detections was the same as in summer 2005/6

\begin{tabular}{|c|c|c|c|c|c|}
\hline \multirow[t]{2}{*}{ Season } & \multirow{2}{*}{$\begin{array}{l}\text { Effort } \\
\text { (d) }\end{array}$} & \multirow{2}{*}{$\begin{array}{c}\text { No. of } \\
\text { detections }\end{array}$} & \multirow{2}{*}{ Binomial } & - Probability & \multirow[b]{2}{*}{$\begin{array}{l}\text { Negative } \\
\text { binomial }\end{array}$} \\
\hline & & & & $\begin{array}{l}\text { Zero-inflated } \\
\text { binomial }\end{array}$ & \\
\hline Summer 2006/7 & 104 & 0 & $4.25 \times 10^{-7}$ & $4.32 \times 10^{-7}$ & $4.04 \times 10^{-7}$ \\
\hline Winter 2007 & 69 & 0 & $5.92 \times 10^{-5}$ & $5.99 \times 10^{-5}$ & $5.73 \times 10^{-5}$ \\
\hline Summer 2007/8 & 135 & 1 & $1.09 \times 10^{-7}$ & $1.21 \times 10^{-7}$ & $2.96 \times 10^{-8}$ \\
\hline Winter 2008 & 50 & 0 & $8.64 \times 10^{-4}$ & $8.72 \times 10^{-4}$ & $8.43 \times 10^{-4}$ \\
\hline
\end{tabular}

The area of Manukau Harbour potentially available to Maui's dolphins was $88.24 \mathrm{~km}^{2}$. The maximum area effectively monitored by the T-PODs was $0.73 \mathrm{~km}^{2}$, or $0.83 \%$ of the available area. Note that this is a maximum, as T-PODs were not deployed at all 6 stations for the duration of the study (Fig. 2).

\section{DISCUSSION}

Passive acoustic monitoring using T-PODs detected Maui's dolphins in Manukau and Kaipara Harbours. Detections which satisfied our decision rules were made on 6 separate days over 2 yr in Manukau Harbour and on $1 \mathrm{~d}$ in Kaipara Harbour. These detections add weight to existing evidence from visual sightings (Slooten et al. 2005) that Maui's dolphins are present in North Island harbours and indicate that passive acoustic monitoring is an option for investigating habitat use by rare species of delphinids.

The acoustic detection from Kaipara Harbour was more than $10 \mathrm{~km}$ beyond the protected area where gillnetting is now prohibited. The acoustic detections from Manukau Harbour were outside the original extent of the protected area designated in 2003. As a result of this study, the protected area was extended in 2008 and now encompasses the location at which the acoustic detections were made. In 2007, it was estimated that 136 gillnetting vessels were operating on the North Island's west coast, with the majority fishing in the harbours, notably Manukau and Kaipara Harbours targeting grey mullet Mugil cephalus, flatfish (principally yellow-belly flounder Rhombosolea leporina) and rig Mustelus lenticulatus (Ministry of Fisheries \& Department of Conservation 2007). This reiterates concerns that Maui's dolphins are vulnerable to bycatch in gillnets in the North Island harbours.

Of the 39 detections which we identified as originating from Maui's dolphins, 37 came from Cornwallis Point in Manukau Harbour during 2005/6, the first year of the study. These data were used to fit 3 models, all of which suggested that the much lower number of detections for the remainder of the study was statistically significant. It is unclear whether the level of use in summer 2005/6 was anomalously high, or whether the subsequent lack of detections was due to a decline in the Maui's dolphin population and/or a contraction of their range. To date there has been only one robust estimate of Maui's dolphin abundance (Slooten et al. 2006) and hence trend data are unavailable. With so few detections, it is not possible to make 
definitive statements about the relative use of the different harbours in the study and whether certain harbours represent preferred habitats and, if so, why.

We chose 'monitoring day' as the sampling unit for the analyses, as a compromise between temporal resolution and independence of the data points. Of the 5 detection positive days at Cornwallis Point in 2005/6, 4 were consecutive. Without additional information on the movements of individual dolphins, it is not possible to ascertain whether these data points are truly independent. However, in the absence of a clearly more suitable sampling unit, we believe that the analyses we have presented are appropriate, with the caveat that some non-independence of the data would probably result in larger $\mathrm{p}$ values.

Our calculations suggest that low levels of use of the monitored habitats could go undetected. For example, during the longest monitoring period (153 d at Kauri Point in Manukau Harbour during winter 2008) there could have been up to $2 \mathrm{~d}$ when Maui's dolphins were in range of the T-PODs, with $>5 \%$ probability of no detections being made. Furthermore, in order for a dolphin to be detected, it must be echolocating, oriented approximately towards the T-POD, and in an acoustic environment which makes detection possible. These requirements further reduce the likelihood of detection. For example, only $68 \%$ of Hector's dolphin groups that came within $100 \mathrm{~m}$ of a T-POD at Banks Peninsula yielded 'Cet All' acoustic detections (Rayment et al. 2009b).

Manukau Harbour received by far the most monitoring effort of all the harbours, and monitoring was focussed on the deeper channels, where we expected higher levels of use. However, the area effectively monitored by the T-PODs was very small, i.e. less than $1 \%$ of the habitat potentially available to Maui's dolphins. How this proportion translates into probability of detection will be a function of the dolphins' movement patterns and echolocation behaviour. The highfrequency signals of small odontocetes attenuate quickly and hence are only detectable over at most a few hundred metres, even in relatively quiet environments (Akamatsu et al. 2001, Philpott et al. 2007, Rayment et al. 2009b). In contrast, the low-frequency calls of baleen whales are detectable over tens or even hundreds of kilometres (Sirovic et al. 2007, Moore et al. 2010). Therefore, acoustic monitoring networks targeting baleen whales can cover ocean basins (e.g. Nieukirk et al. 2004, Sirovic et al. 2004), while for small odontocetes many acoustic monitors would be required to reliably detect individuals over even very limited spatial scales. A good illustration of this comes from efforts to detect changes in abundance of vaquita. Power analyses revealed that a network of 62 C-PODs (an updated version of the T-POD) would be required to detect the target changes in abundance within the $1264 \mathrm{~km}^{2}$ vaquita refuge area (Rojas-Bracho et al. 2010). Given the low densities of Maui's dolphins detected in the North Island harbours during our study, many more T-PODs would be required to investigate spatial and temporal differences in habitat use.

The majority of detections classified as 'Cet All' by the T-POD software were excluded by our decision rules because we could not be certain that they were of cetacean origin. The most common reasons for rejection were spurious noise around the focal click train and PRFs of the click train not changing smoothly, suggesting that high levels of non-biological noise confounded the train detection process. Such noise could be generated by collisions between sediment particles agitated by waves or tidal movements (Thorne 1985). High tidal streams in North Island harbours mean sediment noise may be a significant problem, either by masking genuine dolphin click trains or generating false positive detections. Our solution was to examine each 'Cet All' detection and apply our own set of decision rules, making the analysis more time consuming and potentially more subjective. We believe our decision rules are very conservative and may well have resulted in rejection of genuine Maui's dolphin detections. However, the fact that all of the train characteristics we tested were significantly different between accepted and rejected click trains suggests that there were genuine differences between the 2 classes of data. Further research involving simultaneous visual and acoustic surveys (Rayment et al. 2009b), and a detailed acoustic characterisation of the environment would help to quantify the detection probability of Maui's dolphins.

It is understood that there is variation in sensitivity among T-PODs, especially the older v.3 models (Dähne et al. 2006). This variation can be accounted for with sampling design (e.g. Rayment et al. 2009a) or by calibration of the instruments (e.g. Kyhn et al. 2008). Such considerations would be important in a study investigating trends in habitat use over time or differences between locations. In this study we deemed it of little concern, as we were essentially investigating presence or absence, rather than relative rates of detection. However, future studies involving multiple T-PODs should consider variation in instrument sensitivity in order that results from different locations and times are strictly comparable.

Many of the areas we monitored were characterised by poor underwater visibility $(<1 \mathrm{~m})$, high current speed (ca. $1 \mathrm{~m} \mathrm{~s}^{-1}$ ) and unstable substrates. Due to safety concerns, commercial divers were used to moor T-PODs. To minimise the risk of interference, we attempted to conceal mooring locations by having no surface marker buoy. However, so that we could re- 
locate them, most T-PODs were moored in association with existing navigation marks. Seven T-PODs were lost in this study. The causes of loss appeared to be failure of the attachment system or inadequate care in attachment (4), interference following disclosure of the mooring location (1), removal of a navigation mark so that the T-POD could not be relocated (1), and failure to relocate mooring (1). These losses made calibration of the units impossible and caused gaps in the data. Development of a more reliable mooring system and greater attention to detail from divers attaching the instruments need to be high priorities for any passive acoustic monitoring project.

In light of our results with Maui's dolphins, we make the following recommendations concerning acoustic monitoring studies of rare cetaceans:

(1) The objectives of the monitoring should be clearly defined.

(2) A priori power analysis, accounting for the detection range of the monitoring instruments, would assist in the development of an appropriate sampling design.

(3) An understanding of the target signals and the acoustic environment being monitored is essential for maximising detection rates.

(4) Simultaneous visual and acoustic observations are very helpful in order to relate acoustic detection rates to densities of the target species.

(5) Variation in sensitivity between monitoring instruments should be explicitly tested, or accounted for in the sampling design.

(6) Our decision rules were essential to minimise the potential for false positives, but it would be extremely useful to be able to inspect the waveform of the detected signals. T-PODs or C-PODs could be supplemented by one or more high-frequency acoustic recording packages (HARPs; Wiggins \& Hildebrand 2007), which are self-contained acoustic recorders with the capability to record sounds up to $200 \mathrm{kHz}$ for extended periods (J. Hildebrand pers. comm.).

In conclusion, our study demonstrated that passive acoustic monitoring of Maui's dolphins is possible with T-PODs. The study showed that Maui's dolphins use Manukau and Kaipara Harbours and that the range of Maui's dolphins extends beyond the current protected area. That gillnetting is still permitted in the North Island harbours therefore remains a cause for concern.

Acknowledgements. We are very grateful to B. Maas (Naturschutzbund Deutschland, formerly Care For The Wild) for encouragement and support of this study. Support was provided by the NZ Department of Conservation, NZ Whale and Dolphin Trust, University of Otago, Environment Waikato, NZ Forest and Bird Society and Auckland Regional Council. W.R. is supported by a Foundation for Research Science \& Technology Post-Doctoral Fellowship. N. Tregenza provided T-PODs at heavily discounted rates, and tirelessly answered our many questions. We are grateful to many Department of Conservation staff, particularly D. Breen, P. Brown, K. McLeod, G. Hickman and K. Sivaguru. We thank D. MacKenzie for writing the code to implement the 0-inflated binomial distribution. The manuscript was improved by comments from 3 anonymous reviewers.

\section{LITERATURE CITED}

Akamatsu T, Wang D, Wang K, Wei Z (2001) Comparison between visual and passive acoustic detection of finless porpoises in the Yangtze River, China. J Acoust Soc Am 109:1723-1727

Akamatsu T, Wang D, Wang K, Li S and others (2008) Estimation of the detection probability for Yangtze finless porpoises (Neophocaena phocaenaoides asiaeorientalis) with a passive acoustic method. J Acoust Soc Am 123: 4403-4411

$\mathrm{Au}$ WWL (1993) The sonar of dolphins. Springer-Verlag, New York, NY

> Au WWL, Ford JKB, Horne JK, Newman Allman KA (2004) Echolocation signals of free-ranging killer whales (Orcinus orca) and modelling of foraging for Chinook salmon (Oncorhynchus tshawytscha). J Acoust Soc Am 115: 901-909

Bailey H, Clay G, Coates EA, Lusseau D, Senior B, Thompson PM (2010) Using T-PODs to assess variations in the occurrence of coastal bottlenose dolphins and harbour porpoises. Aquat Conserv 20:150-158

Carstensen J, Henriksen OD, Teilmann J (2006) Impacts of offshore wind farm construction on harbour porpoises: acoustic monitoring of echolocation activity using porpoise detectors (T-PODs). Mar Ecol Prog Ser 321: 295-308

> Clark CW, Brown MW, Corkeron P (2010) Visual and acoustic surveys for North Atlantic right whales, Eubalaena glacialis, in Cape Cod Bay, Massachusetts, 2001-2005: management implications. Mar Mamm Sci 26:837-854

Dähne M, Verfuß UK, Diederichs A, Meding A, Benke H (2006) T-POD test tank calibration and field calibration. In: Leeney RH, Tregenza NJC (eds) Proc Workshop Static Acoustic Monitoring of Cetaceans, 20th Annual Meeting of the European Cetacean Society, Gdynia, Poland, 2 April 2006. European Cetacean Society, Kiel. Available at www. seaturtle.org/mtrg/personnel/SAM_report_ECS_2006.pdf

Dawson SM, Slooten E (1988) Hector's dolphin Cephalorhynchus hectori: distribution and abundance. Rep Int Whal Comm Spec Iss 9:315-324

Hall DB (2000) Zero-inflated Poisson and binomial regression with random effects: a case study. Biometrics 56: 1030-1039

Kyhn LA, Tougaard J, Teilmann J, Wahlberg M, Jørgensen PB, Bech NI (2008) Harbour porpoise (Phocoena phocoena): laboratory detection thresholds of T-PODs are reflected in field sensitivity. J Mar Biol Assoc UK 88: 1085-1091

Ludwig JA, Reynolds JF (1988) Statistical ecology: a primer on methods and computing. John Wiley \& Sons, New York, NY

Mellinger DK, Stafford KM, Moore SE, Dziak RP, Matsumoto $\mathrm{H}$ (2007) An overview of fixed passive acoustic observation methods for cetaceans. Oceanography (Wash DC) 20: $36-45$

Ministry of Fisheries (2008) Final advice and decisions on fisheries measures. Available at www.fish.govt.nz/en-nz/ Consultations/Archive/2008/Hectors+dolphins/Decisions. 
htm?wbc_purpose=Basic\&WBCMODE $=$ P (accessed 7 Dec 2010)

Ministry of Fisheries \& Department of Conservation (2007) Hector's and Maui's dolphin threat management plandraft for public consultation. Ministry of Fisheries \& Department of Conservation, Wellington

Moore SE, Stafford KM, Munger LM (2010) Acoustic and visual surveys for bowhead whales in the western Beaufort and far northeastern Chukchi seas. Deep-Sea Res II 57:153-157

Morisaka T, Karczmarski L, Akamatsu T, Sakai M, Dawson SM, Thornton M (2011) Echolocation signals of Heaviside's dolphins (Cephalorhynchus heavisidii). J Acoust Soc Am 129:449-457

Nieukirk SL, Stafford KM, Mellinger DK, Dziak RP, Fox CG (2004) Low-frequency whale and seismic airgun sounds recorded in the mid-Atlantic Ocean. J Acoust Soc Am 115: $1832-1843$

Philpott E, Englund A, Ingram S, Rogan E (2007) Using TPODs to investigate the echolocation of coastal bottlenose dolphins. J Mar Biol Assoc UK 87:11-17

Rayment W, Dawson S, Slooten E (2009a) Use of T-PODs for acoustic monitoring of Cephalorhynchus dolphins: a case study with Hector's dolphins in a marine protected area. Endang Species Res 10:333-339

Rayment W, Dawson S, Slooten E (2009b) Trialling an automated passive acoustic detector (T-POD) with Hector's dolphins (Cephalorhynchus hectori). J Mar Biol Assoc UK 89:1015-1022

Rayment W, Dawson S, Slooten E (2010) Seasonal changes in distribution of Hector's dolphin at Banks Peninsula, New Zealand: implications for protected area design. Aquat Conserv 20:106-116

Reeves RR, Dawson SM, Jefferson TA, Karczmarski L and others (2008) Cephalorhynchus hectori ssp. maui. In: IUCN (2011) IUCN Red List of Threatened Species. Version 2011.1. Available at www.iucnredlist.org (accessed 2 Jul 2011)

Rojas-Bracho L, Reeves RR, Jaramillo-Legorreta A, Taylor BL (2008) Phocoena sinus. In: IUCN (2011) IUCN Red List of Threatened Species. Version 2011.1. Available at www. iucnredlist.org (accessed 2 Jul 2011)

Rojas-Bracho L, Jaramillo-Legorreta AM, Taylor BL, Barlow J and others (2010) Assessing trends in abundance for vaquita using acoustic monitoring: within refuge plan and

Editorial responsibility: Sascha Hooker,

St. Andrews, UK outside refuge research needs. Paper SC/62/SM5 presented to the IWC Scientific Committee. Available at http://iwcoffice.org/_documents/sci_com/SC62docs/SC-62SM5.pdf (accessed 2 Jul 2011)

> Sirovic A, Hildebrand JA, Wiggins SM, McDonald MA, Moore SE, Thiele D (2004) Seasonality of blue and fin whale calls and influence of sea ice in the Western Antarctic Peninsula. Deep-Sea Res II 51:2327-2344

Sirovic A, Hildebrand JA, Wiggins SM (2007) Blue and fin whale call source levels and propagation range in the Southern Ocean. J Acoust Soc Am 122:1208-1215

Slooten E (2007) Conservation management in the face of uncertainty: effectiveness of four options for managing Hector's dolphin bycatch. Endang Species Res 3: 169-179

Slooten E, Dawson SM (2010) Assessing the effectiveness of conservation management decisions: likely effects of new protection measures for Hector's dolphin (Cephalorhynchus hectori). Aquat Conserv 20:334-347

Slooten E, Dawson SM, Rayment WJ, Childerhouse SJ (2005) Distribution of Maui's dolphin, Cephalorhynchus hectori maui. New Zealand Fisheries Assessment Report 2005/28, Ministry of Fisheries, Wellington

Slooten E, Dawson S, Rayment W, Childerhouse S (2006) A new abundance estimate for Maui's dolphin: What does it mean for managing this critically endangered species? Biol Conserv 128:576-581

Taylor BL, Gerrodette T (1993) The uses of statistical power in conservation biology: the vaquita and northern spotted owl. Conserv Biol 7:489-500

Thorne PD (1985) The measurement of acoustic noise generated by moving artificial sediments. J Acoust Soc Am 78:1013-1023

> Verfuß UK, Honnef CG, Meding A, Dähne M, Mundry R, Benke H (2007) Geographical and seasonal variation of harbour porpoise (Phocoena phocoena) presence in the German Baltic Sea revealed by passive acoustic monitoring. J Mar Biol Assoc UK 87:165-176

Wiggins SA, Hildebrand JA (2007) High-frequency Acoustic Recording Package (HARP) for broad-band, long-term marine mammal monitoring. International Symposium on Underwater Technology 2007 and International Workshop on Scientific Use of Submarine Cables and Related Technologies 2007. Institute of Electrical and Electronics Engineers, Tokyo, p 551-557

Submitted: January 10, 2011; Accepted: May 15, 2011

Proofs received from author(s): July 2, 2011 